\title{
Milk bolus obstruction in the neonate
}

\author{
C. T. LEWIS, J. A. S. DICKSON, AND V. A. J. SWAIN
}

From Queen Elizabeth Hospital for Children, London

SUMMARY Seventeen cases of neonatal intestinal obstruction due to inspissated milk curds were seen at this hospital in the 9 years 1964-1972. The obstruction started on the 2 nd to 10th day of life. Half the babies passed blood from the rectum and in most the $x$-rays were diagnostic. All survived, 14 after operation and 3 after medical treatment with a Gastrografin enema. Incomplete absorption of solids, particularly the fat from cows' milk feeds, is suggested as the cause.

Intestinal obstruction in neonates due to inspissated milk curds was first reported by Cook and Rickham (1969), and Cremin et al. (1970) have given a detailed description of the radiological appearances and the use of Gastrografin as an enema to relieve the obstruction. The condition was first seen at this hospital in 1964, and by 1970 it was clear that it was an important new disease which was being seen with increasing frequency (Fig.). This review was

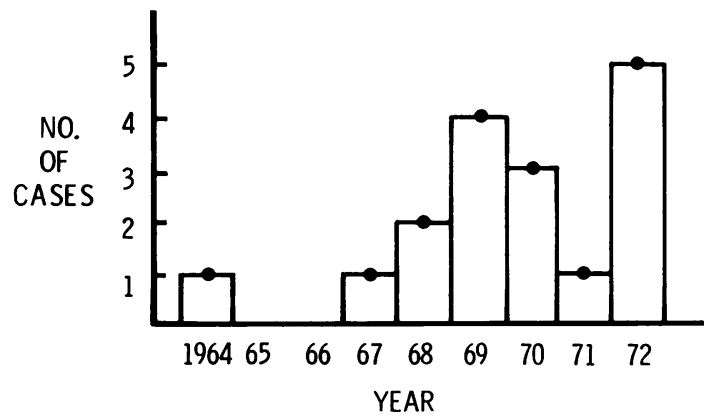

Fig. Annual incidence of milk plug obstruction at Queen Elizabeth Hospital, London.

then started to establish the clinical picture, the treatment and, if possible, the causes of the obstruction.

\section{Patients}

In the 9 years, 1964-1972, 445 neonates with intestinal obstruction were treated at this hospital of whom $17(6 \%)$ suffered from milk curd obstruc-

Received 15 April 1976 tion. Search of the records back to 1954 failed to show any earlier cases.

The first 14 cases in the series were treated by operation; the last 3 medically. Detailed analysis was restricted to the first $\mathbf{1 4}$ cases, as the diagnosis was certain and the follow-up longest.

Sex. There were 13 boys and only one girl in this group. There is no obvious explanation for this difference, which is highly significant $(P<0.005)$ when compared with a controlled series of 100 unselected neonatal intestinal obstructions.

Maturity. 5 of the babies were preterm by dates but only 3 were $<2.5 \mathrm{~kg}$ in weight. The range of weights was $2 \cdot 04-5 \cdot 69 \mathrm{~kg}$, with a mean of $2.95 \mathrm{~kg}$.

Blood groups. The blood groups of the babies were within the range to be expected in a random sample taken in England.

Pregnancy and drugs. There were no common factors in the pregnancies, and no associations with drugs administered to the mothers during pregnancy or labour, or to the babies after birth.

\section{Clinical presentation}

Onset. The day of onset of the obstruction varied from the 2nd to 10th day of life with a peak around the 5th and 6th days. The signs and symptoms were those of an acute small bowel obstruction. After passing meconium followed by a normal changing stool the babies stopped passing stools, became distended, refused feeds, and developed bile-stained vomiting. In half the babies blood was passed from the rectum or was seen on the examining 
finger. A mass was palpable in the right lower quadrant on five occasions.

\section{Radiology}

Abdominal $x$-rays were taken of 11 of the babies; though no correct preoperative diagnosis was made, in retrospect the plain supine and erect films often showed diagnostic features. (i) Low small bowel fluid levels (11/11). (ii) Absence of the normal gas pattern from the right lower quadrant of the abdomen (10/11). This was replaced by an impression of a faecal mass containing bubbles and crescents of fat and gas (7/11). These appearances are similar to those described by Cremin et al. (1970). (iii) Gas was present in the rectum in $8 / 11$.

The full picture may be diagnostic but can be mimicked in Hirschsprung's disease. A Gastrografin (Schering) enema, as recommended in meconium ileus (Noblett, 1969; Lillie and Chrispin, 1972), will establish the diagnosis and may in many instances relieve the obstruction (Cremin et al., 1970). An enema is preferable to oral administration as it is more reliable for the diagnosis or exclusion of Hirschsprung's disease and enterocolitis.

\section{Operation}

In the 14 cases operated on the abdomen was opened through a supraumbilical transverse incision. The cause of the obstruction was in the majority a 'milk plug' impacted in the terminal ileum near the ileocaecal valve. In 2 cases it extended more proximally, in 2 it was localized in the mid-ileum, and in only 1 did it extend into the colon. One baby had a perforated appendix similar to that described by Broadbent and Jardine (1971). On four occasions perforation of the ileum over the bolus seemed imminent and the bowel was cleared through an enterotomy and in one of these a temporary ileostomy was performed. In the others the bolus was broken up through the bowel wall, occasionally assisted by intraluminal injection of isotonic saline, and milked through the ileocaecal valve into the colon.

Postoperative progress, with the exception of one wound disruption, was uneventful. There were no postoperative deaths. The babies were regraded onto an SMA (Wyeth) feed as quickly as possible, and thereafter fed normally. Mixed feeding was introduced at the normal time around 3 months of age. All the children have been followed up routinely in the outpatient clinic and the long-term progress has been satisfactory with two exceptions, a very small preterm baby and an Amsterdam dwarf (Cornelia de Lange syndrome).
Further investigations included the following. Sweat sodium was measured to exclude cystic fibrosis in all the babies. Tryptic activity of the stools was assayed in the majority and was normal. In 5 babies biopsies were taken from the wall of the collapsed gut distal to the obstruction; ganglion cells were present.

\section{Discussion}

The cause of the obstruction appears to be differential absorption of the water and solid content of the milk leaving a plasticine-like or gritty bolus which impacts in the lower small bowel. The problem has been approached from two aspects, a possible lessened ability of the baby to digest the milk solids or deficiencies in the milk.

Milks. The types of milk feed given to the children before the obstruction are shown in Table $I$ and compared with the feeds given to a group similar in

Table 1 Feeding regimens immediately preceding milk plug obstruction compared with a control group treated for hernia

\begin{tabular}{lll}
\hline & $\begin{array}{l}\text { Milk plug } \\
\text { group }\end{array}$ & $\begin{array}{l}\text { Control } \\
\text { group }\end{array}$ \\
\hline Ostermilk 2 & $8^{*}$ & 2 \\
Ostermilk 1 & 1 & 0 \\
Baby Milk 2 $\dagger$ & 2 & 3 \\
Full-Cream Carnation & 1 & 0 \\
Full-Cream National Dried & 0 & 1 \\
Full-Cream Totals & $12^{*}$ & 6 \\
Baby Milk 1† & 1 & 0 \\
SMA & 1 & 4 \\
Expressed breast milk & 0 & 1 \\
Breast & 0 & 3 \\
Totals & 14 & 14 \\
\hline
\end{tabular}

*Significant at $5 \%$ level. †Cow and Gate.

age and sex distribution who were treated during the same period for inguinal hernia. If the 2 abnormal babies, one very premature on SMA feed and the Amsterdam dwarf on full-cream Carnation milk, are excluded, 10 out of 12 babies were on a fullcream powder milk feed compared with 6 out of 14 in the control group. This difference is significant at the $5 \%$ level. The frequency with which Ostermilk 2 was involved was significant when compared with the control series but not when compared with the milk consumption figures for South East England (Table 2). Figures for the proportion of babies fed in South East England on full-cream cows' milk formulae in the first week of life are not available. 
Table 2 Milks given to babies with 'plugs' compared with area average consumption in South East England

\begin{tabular}{llll}
\hline & 'Plugs' (\%) & $\begin{array}{l}\text { Area average } \\
(\%)\end{array}$ & Controls (\%) \\
\hline Ostermilk 2 & 57 & 41 & 14 \\
Baby Milk 2* & 14 & 36 & 22 \\
SMA & 7 & 15 & 29 \\
\hline
\end{tabular}

*Cow and Gate.

The babies. There appear to be two groups. (i) Very small or very sick babies in whom the obstruction is part of the general disease and may occur with any milk other than human breast milk. (ii) Normal babies fed on reconstituted powdered cows' milk with the fat as butter fat. In the latter group fullcream milks have been most frequently implicated; more rarely half-cream milks have been responsible.

Cook and Rickham (1969) studied glucose, xylose, glycine, and gelatin absorption postoperatively in 4 babies, and upon repeating this test after 10 to 12 months found neonatal deficiencies had returned to normal. We performed casein load tests followed by ion exchange chromatography of plasma amino acids on 2 babies. With the exception of alanine, the absorption of all amino acids tested was deficient. As the results of this test performed shortly after an intestinal obstruction are difficult to interpret, and repeat testing on children who were thriving on normal diets was not considered ethical, this investigation was stopped.

In one child a complete 5-day metabolic balance was performed after normal feeding on SMA had been established. This showed a slightly low retention of nitrogen at around $51 \%$ and a fat absorption of only $60 \%$. The difficulties involved in a total metabolic balance prevent this being used as a routine investigation. The normal values for fat absorption from different milks as established by Southgate et al. (1969) (Table 3) show that the newborn human

Table 3 Fat absorption for different milks (Southgate et al., 1973)

\begin{tabular}{ll}
\hline Milk & $\%$ fat retention $($ mean $\pm S D)$ \\
\hline Breast milk & $92 \cdot 3 \pm 5 \cdot 2$ \\
SMA/S 26 & $88 \cdot 5 \pm 2 \cdot 2$ \\
B & $80 \cdot 0 \pm 8 \cdot 1$ \\
D & $65 \cdot 5 \pm 10 \cdot 3$ \\
Ostermilk & 6 \\
\hline
\end{tabular}

infant absorbs fat best from breast milk but is less able to absorb butter fat, and justify the traditional practice in the artificial feeding of neonates of starting with half-cream milks. It is likely that this defective absorption of butter fat, possibly with the formation of a calcium soap in the gut lumen, is the explanation for the obstruction. This hypothesis would explain the frequency with which full-cream milks were involved, and is supported by the low fat absorption in the baby tested and by analysis of plugs obtained almost intact after conservative management with Gastrografin enemas. In Table 4 the

Table 4 Analysis of plugs from three babies-dry composition $\mathrm{g} / 100 \mathrm{~g}$ and water content

\begin{tabular}{lllll}
\hline & Plug 1 & Plug 2 & Plug 3 & Ostermilk 2 \\
\hline Fat & 59 & 67 & 56 & $26 \cdot 5$ \\
Protein & 11 & $6 \cdot 5$ & - & $26 \cdot 5$ \\
Calcium & $6 \cdot 4$ & $5 \cdot 5$ & $4 \cdot 7$ & $1 \cdot 0$ \\
$\begin{array}{l}\text { Phosphorus } \\
\text { Water }\end{array}$ & $1 \cdot 1$ & 0.46 & - & $0 \cdot 8$ \\
$\quad$ content (\%) & 63 & 74 & 79 & - \\
\hline
\end{tabular}

analyses of three plugs are compared with that of Ostermilk 2, confirming the increase in fat and calcium content in the 'plugs'.

The possibility of dehydration playing a part in the condition was investigated. There was no seasonal incidence, but as the temperature and humidity in baby nurseries are kept fairly constant this was not expected. The greater solute load of cows' milk could also lead to relatively early 'drying out' of the intestinal content. The demonstration by Wilkinson et al. (1973) of the difficulties of preparing a powder milk feed correctly tempts speculation that overconcentration of the feeds may have played a part. The possibility of an association with necrotizing enterocolitis has been suggested (J. Lister, personal communication, 1973). That there is an area of overlap of the milk bolus obstruction and necrotizing enterocolitis seems possible (Dickson, 1975), and the case of neonatal appendicitis reported by Broadbent and Jardine (1971) can be explained on this basis. However, this is not an acceptable explanation for the cases in this series as the only diagnostic radiographic feature-submucosal gas (Hodson, 1975) - was not seen.

Both Ostermilk and Cow and Gate milk were roller-dried at the time these obstructions occurred so it is impossible to comment on the possible relative effects of roller- and spray-drying of the milk powder (British Medical Journal, 1969). No cases have so far been seen in babies fed on liquid prepacked milk feeds.

No satisfactory explanation can be given of why this obstruction should have appeared around 1964 1965 in both the United Kingdom and South Africa. Earlier feeding of preterm babies does not apply to most of our cases, but there does seem to have been a trend towards feeding term babies from birth on full-cream milks. 


\section{References}

British Medical Journal (1969). New hazards for the newborn, 4, 633-634.

Broadbent, N. R. G., and Jardine, J. L. (1971). Acute appendicitis in a premature infant: a case report. Australian and New Zealand Journal of Surgery, 40, 362-364.

Cook, R. C. M., and Rickham, P. P. (1969). Neonatal intestinal obstruction due to milk curds. Journal of Pediatric Surgery, 4, 599-605.

Cremin, B. J., Smythe, P. M., and Cywes, S. (1970). The radiological appearance of the 'inspissated milk syndrome'; a cause of intestinal obstruction in infants. British Journal of Radiology, 43, 856-858.

Dickson, J. A. S. (1975). Keynote address: necrotising enterocolitis in the newborn infant. Report of the SixtyEighth Ross Conference on Pediatric Research, p. 13. Ed. by T. D. Moore. Ross Laboratories, Columbus, Ohio. Hodson, W. A. (1975). Diagnosis and clinical criteria for recognition. Report of the Sixty-Eighth Ross Conference on Pediatric Research, p. 19. Ed. by T. D. Moore. Ross Laboratories, Columbus, Ohio.

Lillie, J. G., and Chrispin, A. R. (1972). Investigations and management of neonatal obstruction by Gastrografin enema. Annales de Radiologie, 15, 237-241.

Noblett, H. R., (1969). Treatment of uncomplicated meconium ileus by Gastrografin enema: a preliminary report. Journal of Pediatric Surgery, 4, 190-197.

Southgate, D. A. T., Widdowson, E. M., Smits, B. J., Cooke, W. T., Walker, C. H. M., and Mathers, N. P. (1969). Absorption and excretion of calcium and fat by young infants. Lancet, 1, 487-489.

Wilkinson, P. W., Noble, T. C., Gray, G., and Spence, O. (1973). Inaccuracies in measurement of dried milk powders. British Medical Journal, 2, 15-17.

Correspondence to Mr. C. T. Lewis, Department of Thoracic Surgery, The London Hospital, Whitechapel, London E1 1BB. 